\title{
THE ANTIKYTHERA MECHANISM: From the bottom of the sea to the scrutiny of modern technology
}

\author{
John H. Seiradakis ${ }^{1}$ \\ Aristotle University \\ Department of Physics \\ Laboratory of Astronomy \\ GR-541 24, Thessaloniki, Greece \\ E-mail: jhs@physics.auth.gr
}

\begin{abstract}
The Antikythera Mechanism is an ancient greek analogue astronomical computer. Using a handle, probably similar to a doorknob, the user could insert an input date on a dial in its front side. The calculations were made using a set of gears (at least 30), and the results were displayed on several scientific scales. It was used to calculate the diurnal and annual motion of the Sun, the Moon and (most probably) the planets among the stars. It put into practice the astronomical knowledge of ancient Greeks about the motion of these objects with astonishing accuracy, including eccentric gearing for the anomalous orbit of the Moon (first lunar anomaly). It could also predict eclipses of the Sun and the Moon from the Saros period, which has been found in one of its back scales. It calculated the dates of the Olympic Games (and the other major crown games that took place in ancient Greece). Finally it was equipped with extended Dorian inscriptions, often quoted as User's Manual. Its complexity and multiple functions indicate that it was not used for a single purpose. I strongly believe that its main use was for educational purposes. The Antikythera Mechanism was as important for the development of Technology, as the Parthenon for the development of Architecture. Taking into account the theoretical and technological knowledge required for the construction of the Mechanism, it can easily be ranked among the Wonders of the Ancient World.
\end{abstract}

\section{The discovery}

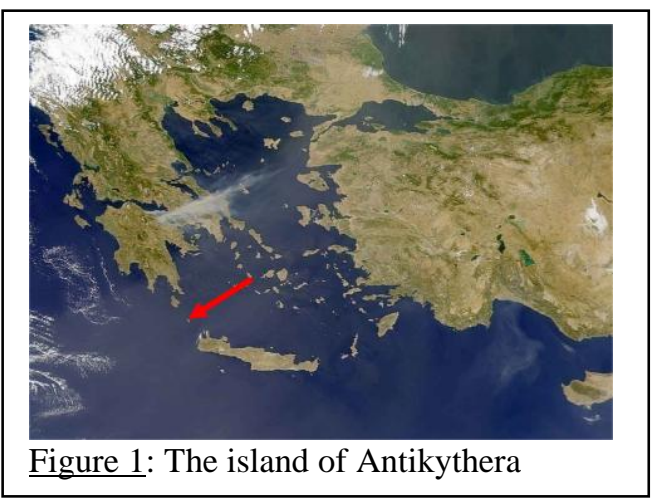

The Antikythera Mechanism was found by chance close to the small island of Antikythera (between Crete and Peloponnese, Fig. 1) in April 1900 by sponge divers, who were stranded there, due to bad weather. A wealth of statues, statuettes, household goods, glassware and amphorae were brought to the surface during tough and brave marine excavations between November 1900 and September 1901.

From Antikythera to the Square Kilometre Array: Lessons from the Ancients, Kerastari, Greece

12-15 June 2012

Speaker 
Among the recovered artifacts was a strange bulk of material, broken, worn and calcified, with obvious signs of bronze. In the first scholarly description of the Antikythera shipwreck and its findings, the existence of the Mechanism was mentioned with the suggestion that it was an astronomical instrument [1]. The shipwreck was dated from between 84 and 67 BCE [2-6].

\section{A short description}

The Antikythera Mechanism was portable. Its size was not much larger than a present-day

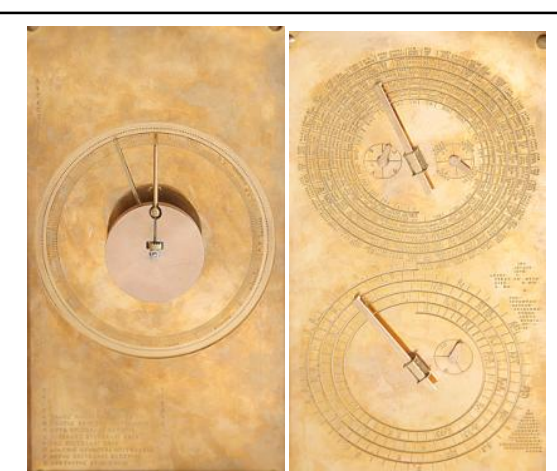

Figure 2: The front and back side of the Antikythera Mechanism.

laptop computer (probably $32 \times 20 \times 10 \mathrm{~cm}$ ). The main feature on the front side was a bronze dial with two concentric annuli (Fig. 2). The outer annulus was not fixed and bore the names of the twelve Egyptian months, inscribed with greek letters. It was divided into $365(360+5$ epagomenae $)$ days. The inner annulus was fixed and bore the names of the 12 zodiac constellations (in greek). It had 360 divisions (360 degrees). In order to take into account leap years, every 4 years, the user could detach and rotate the outer annulus by one day. The back of the Mechanism had two independent spirals (upper and lower). It has been dated, by epigraphologists, around the second half of the $2^{\text {nd }}$ century $\mathrm{BCE}(150 \mathrm{BCE}-100 \mathrm{BCE})$. About this time the great greek astronomer, Hipparchos, lived in Rhodes. He died there in 120 BCE.

\section{Early studies}

In 1929 Captain Ioannis Theopanidis attempted to create a model of the Antikythera Mechanism. This model was never finished. It has been exhibited in the Antikythera Shipwreck exhibition at the National Archaeological Museum [7].

The first scholar, who studied the function of the Mechanism extensively, was Derek de Solla-Price, an Englishman working at Yale University in the United States. With the help of Charalambos Karakalos, from the Research Centre Demokritos in Athens, he obtained gammaand X-ray radiographs from the fragments, which revealed several gears, shafts, axles and letters. Price worked for over 30 years and eventually published an extensive account, "Gears from the Greeks" [8]. He declared that "the Antikythera Mechanism is tantalizing evidence that the ancients may have been much further advanced in machine building, and particularly in computer technology, than we think" [9].

M. Roumeliotis has produced several animations and simulations of the Antikythera Mechanism, freely available on the Internet [10].

The baton was taken by Michael Wright and Alan Bromley [11, 12]. Unfortunately, Alan Bromley died in 2002. However, Michael Wright published a series of papers, where he correctly postulated that the back dials of the Mechanism were spiral and that the upper dial was built to follow the Draconic lunar month. He also elaborated on the pin and slot mechanism (see 
below) and proved its epicyclic function [13-15]. He made large strides toward the reconstruction of the Mechanism and produced superb bronze replicas.

\section{Recent studies - Innovative techniques}

In 2001, Mike Edmunds and Tony Freeth (Cardiff University), Xenophon Moussas and Yanis Bitsakis (University of Athens) and John Seiradakis (University of Thessaloniki) created the "Antikythera Mechanism Research Group". They received a grant from the Leverhulme Foundation, U.K. and the permission to undertake a new investigation from the Ministry of Culture of Greece. After the permission was granted, Eleni Magkou and Mary Zafeiropoulou (National Archaeological Museum) and Agamemnon Tselikas (Cultural Foundation of the National Bank of Greece) joined the team, which was soon supported by an international team of astronomers, archaeologists, mathematicians, physicists, chemists, computer engineers epigraphologists and papyrologists. In September and October 2005 they undertook a major new investigation of the Antikythera Mechanism, using an innovative and state of the art high power micro-focusing X-ray tomography [16], specially constructed by X-Tek Systems, UK and the Hewlett Packard, USA, PTM Dome techniqu3 [17]. In November 2006 the results of the investigation were announced during an international conference in Athens and published in the international journal Nature [18].

\section{Astronomical phenomena calculated by the Antikythera Mechanism}

The results of the new investigation were surprising and stunning! Using a handle that was driving a pointer, the user of the Mechanism could manually select a date of the year in the front dial. As this was done, a set of other pointers were driven by the gears of the Mechanism to show a variety of astronomical phenomena.

\subsection{The front side}

A very careful analysis of the gears' co-action revealed their use in calculating the exact (within a degree) position of the Sun and the Moon and probably the five known planets on the zodiac (the zone that contains the zodiac constellations) [19]. This position was shown by the pointers of the front dials. Simultaneously, a crown gear was driving a black and white coloured spherule, showing the current phase of the Moon.

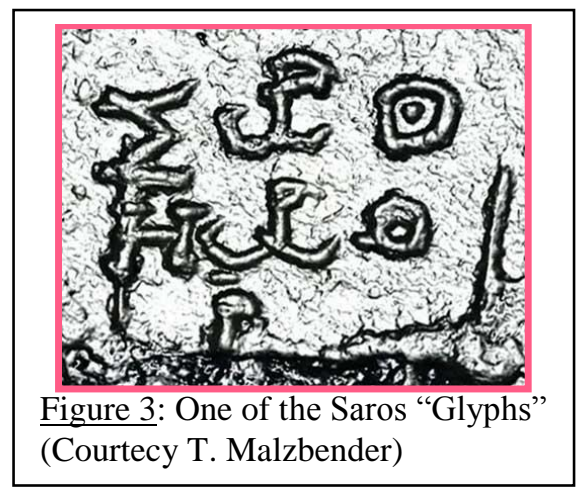

\subsection{The back side}

With the help of the upper back dial, the user could read the position of the Moon within the Metonic cycle of 19 tropical years, which is almost exactly equal to 235 synodic (lunar) months. The Metonic cycle is almost equal to the least common multiple of the tropical year (365.2422 days) and the synodic month 
(29.5306 days). The difference between the two periods (of 19 tropical years and 235 synodic months) is only 2 hours. This knowledge allowed the calculation of the exact day of full Moons, a very useful knowledge for agricultural or nautical activities 2000 years ago, when no ...electricity was available! The accuracy of the position of the Moon was achieved by a pinand-slot mechanism that reconstructed Hipparchus' first anomaly of the Moon's motion (due to its elliptical orbit around the Earth). This anomaly is, in fact, what we call today, Kepler's $2^{\text {nd }}$ law! The basic pin-and-slot mechanism consisted of a gear with a pin, driving a similar (with the same numbers of teeth) gear with a slot. The axes of the two gears are slightly eccentric (by $1.1 \mathrm{~mm}$ ). As the first gear rotates it drives the second gear, slower or faster (because the pin of the first gear is engaged - through the slot- either close to the centre or close to the periphery of the second gear) due to the eccentricity of their axes. The variable rotation speed of the second gear simulates the variations in the Moon's angular velocity, as seen from the Earth, to better than 1 part in 200 [20].

With the help of the lower back dial the user could predict eclipses. This dial contained the 223-month eclipse Saros cycle (of approximately 6585.3213 days, or nearly 18 years and 11 1/3 days). 223 months (one Saros cycle) after an eclipse, the Sun, Earth, and Moon return to approximately the same relative geometry, and a new, nearly identical, eclipse cycle begins. The Saros cycle was marked with the dates (month, day, hour) when a possible solar or lunar eclipse would occur. The markings (which had originally dubbed as "glyphs", before realizing their meaning) were engraved with symbols ("H" - H $\Lambda \mathrm{IO} \Sigma$ - for the Sun and " $\Sigma$ " - $\Sigma \mathrm{E} \Lambda \mathrm{HNH}$ - for the Moon, etc), Fig. 3. The fact that both letters, "H" and " $\Sigma$ ", appear simultaneously in some glyphs, most probably means that the glyphs represent predictions of future eclipses and not records of past eclipses. M. Edmunds [21] has questioned the accuracy of the Saros period.

\section{The Corinthian calendar}

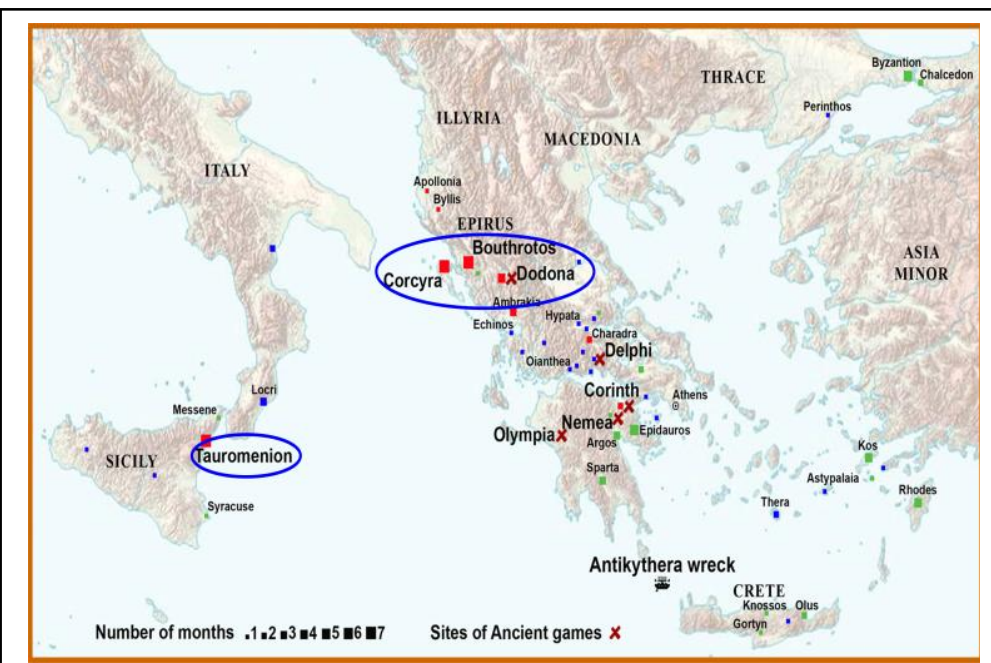

Figure 4: Map showing the location of greek cities with known calendars. The area of the squares is proportional to the percentage of coincidence with the Antikythera Mechanism's calendar (Courtesy M. Anastasiou)
The Metonic cycle (upper back dial) contained a full calendar (repeated 19 times). Comparing this calendar with the known calendars of ancient greek cities, it was found that it coincided with the calendars of the cities of Kerkyra, Bouthrotos and Dodona (in NW Greece) and Tauromenion (in Sicily), all of which are Corinthian colonies (Fig. 4 and Table I). No significant coincidence with the 
survived calendars of other greek cities was found. Could this indicate that the Antikythera Mechanism was used (but not, necessarily, constructed) in NW Greece and Tauromenion?

TABLE I: Comparison of the Antikythera Mechanism calendar with the calendar of several ancient cities. Differences are marked with red letters.

\begin{tabular}{|c|c|c|c|c|c|c|}
\hline $\begin{array}{l}\text { Antikythera } \\
\text { Mechanism }\end{array}$ & Kerkyra & Dodona & Bouthrotos & Tauromenion & Athens & Rhodes \\
\hline ФOINIKAIO & ФOINIKAIOE & ФOINIKAIOE & ФOINIKAIOL & ITSNIOE & 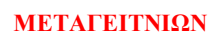 & KAPNEIO 2 \\
\hline KPANEIO & & & KPANEIO & KAPNEIO & 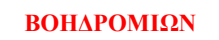 & $\triangle \mathrm{A} \Lambda \mathrm{IO} \mathbf{\Sigma}$ \\
\hline 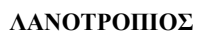 & & 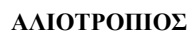 & & 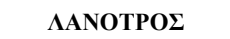 & 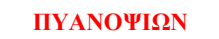 & 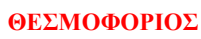 \\
\hline MAXANEY & MAXANEY & AATYIOE & & AПO $\Lambda \Omega N I O \Sigma$ & 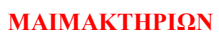 & $\triangle \mathrm{IO \Sigma} \Theta Y O \Sigma$ \\
\hline$\Delta \Omega \Delta E K A T E Y \Sigma$ & $\Delta \Omega \Delta E K A T E Y \Sigma$ & & & $\Delta Y \Omega / O \Delta E K A T E Y \Sigma$ & 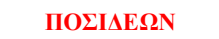 & 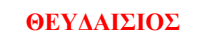 \\
\hline EYKAEIOE & EYKAEIOহ & & EYKAEIOহ & 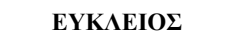 & 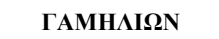 & ПЕААГEITNIO \\
\hline 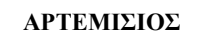 & APTEMITIOE & & & 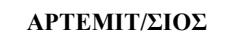 & AN@E & 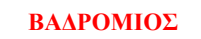 \\
\hline YYAPEY & YYAPEY & & YYAPEY & 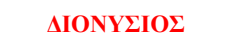 & 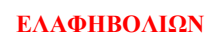 & 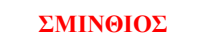 \\
\hline 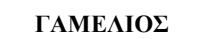 & & ГАМIAIOL & ГАМIAIOІ & 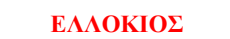 & MOYNYXISN & APTAMITIOE \\
\hline AГPIANIOE & & & AГPIANIOE & 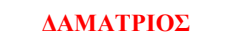 & 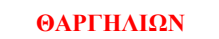 & AГPIANIOE \\
\hline ПАNAMOE & ПАNAMO & ПАNAMO & ПANAMO & 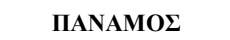 & 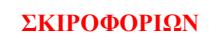 & 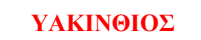 \\
\hline 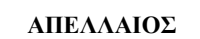 & & 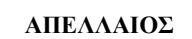 & & 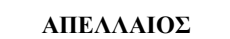 & 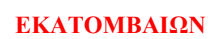 & 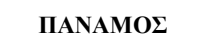 \\
\hline Coincidence & $100 \%$ & $86 \%$ & $100 \%$ & $\mathbf{5 8 \%}$ & $17 \%$ & $33 \%$ \\
\hline
\end{tabular}

\section{The Parapegma of the Antikythera Mechanism}

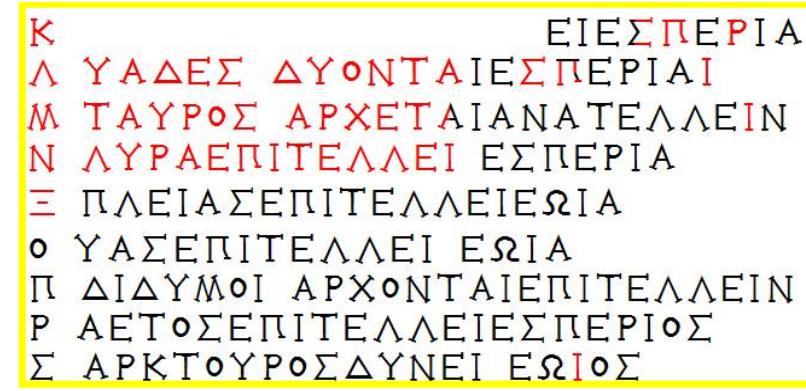

A small part of a parapegma, with six star events and three zodiac statements, is preserved on Fragment $\mathrm{C}$ of the Antikythera Mechanism (Fig. 5). The sequence of these events and statements depends on the geographical latitude, where they were observed. A thorough astronomical analysis reveals that the parapegma was best working for geographic latitudes between $33.3^{\circ} \mathrm{N}-$ $37.0^{\circ} \mathrm{N}$. Several ancient greek cities lie within or immediately adjacent to this zone. Among these cities, Rhodes (latitude $\left.36.4^{\circ} \mathrm{N}\right)$ and Syracuse $\left(37.1^{\circ} \mathrm{N}\right)$ have often been suggested as places of origin and/or use of the Antikythera Mechanism . The northern cities in Epirus, Kerkyra $\left(39.6^{\circ} \mathrm{N}\right)$, Dodona $\left(39.5^{\circ}\right)$, and Bouthrotos $\left(39.7^{\circ}\right)$, whose month names well match the luni-solar calendar of the Mechanism, seem not to be favored. Corinth $\left(37.9^{\circ}\right)$ as well as Tauromenion in Sicily $\left(37.8^{\circ}\right)$ lie just outside the 
most likely zone. However, it should be stressed that (a) the limited preserved events and (b) the historical uncertainties do not allow a firm statement, about the geographic association of the Antikythera Mechanism, to be made but they rather point to a likely region instead. In order to test and verify the method of analysis, Ptolemy's parapegma for Clima 14 was analyzed, yielding a geographical latitude range $27.8^{\circ} \mathrm{N}-31.5^{\circ} \mathrm{N}$, in good agreement with the location where Ptolemy lived and observed [22].

\section{The Olympic Games (and other crown games)}

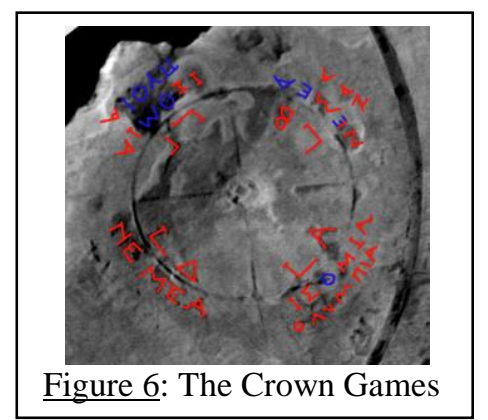

It is interesting that besides the prediction of astronomical events, the Antikythera Mechanism, could determine, with the help of a subsidiary back dial, the dates of the Olympic games which took place during the first full Moon after the summer solstice. Not only the Olympic games but the crown games of Isthmia (Corinth), Nemea (Nemea), Pythia (Delphi), Naia (Dodona) (Fig. 6) were included in the subsidiary dial [23].

\section{Inscriptions - the User's manual}

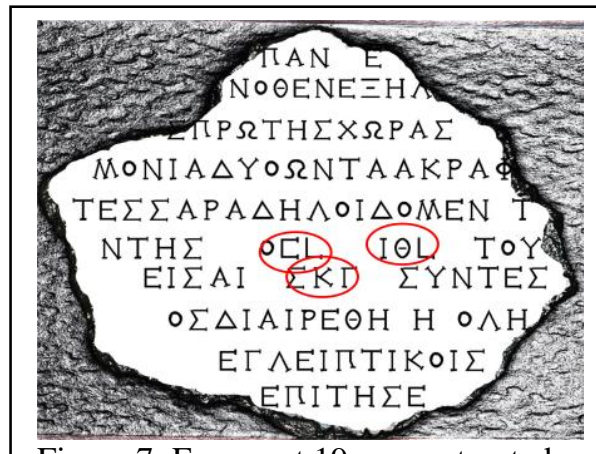

Figure 7: Fragment 19, reconstructed using the new True Type font. Note the Metonic and Saros inscriptions

The Antikythera Mechanism was a complicated instrument. Therefore it is not surprising that it was accompanied by extensive inscriptions, which are often quoted as User's Manual. New inscriptions that had not been read for more than 2000 years were revealed, mainly with the $\mathrm{X}$-ray micro-focusing tomography. About 3000 letters have been deciphered up to now - 2012 (Fig. 7). They all fall into three broad categories: astronomical inscriptions, technical inscriptions and geographical inscriptions. Several astronomical terms have been read referring to the Sun, the Moon, the ecliptic, the Metonic and Saros

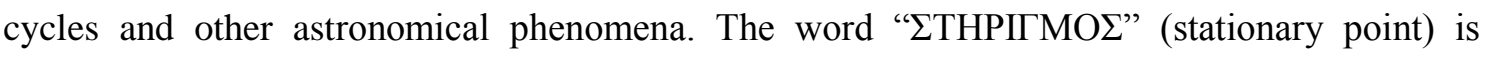
mentioned several times, obviously referring to planetary stationary points.
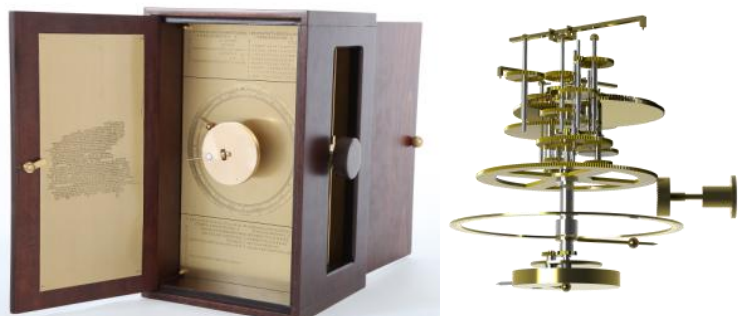

Figure 8. The Aristotle University of Thessaloniki bronze model. (a) Left The constructed model. (b) The gears inside the model.

\section{The Aristotle University} bronze model

A bronze model of the Antikythera Mechanism has been constructed [24] by the Aristotle University of Thessalonliki, Greece 
team, lead by K. Efstathiou (Department of Mechanical Engineering). This model is a 1:1 reconstruction of the original mechanism (Fig. 8). A new true type font, an exact replica of the letters inscribed on the Mechanism, was created by M. Anastasiou (Department of Physics) which was used for reproducing all the inscriptions that have been read up to now.

\section{Concluding remarks}

According to the modern definition, the Antikythera Mechanism was a computer. The user could enter data (input), it used the data in order to calculate several astronomical and related phenomena (calculations) and the results were displayed on scientific scales (output). The calculations were performed by trains of cooperating gears that drove at least seven pointers, which showed the results quantitatively. It was an astronomical device. It could calculate the position of the Sun and the Moon and maybe the five known planets along the ecliptic (the zodiac constellations) and displayed the phases of the Moon. It was also a calendrical device incorporating the Metonic lunisolar cycle and a parapegma. It predicted eclipses, a result that would give social superiority to the owner. With it, the owner could determine the dates of the Crown Games (the most famous of which are the Olympic Games) achieving wide recognition among the ancient cities' archons. It demonstrated with outstanding and creative technological competence the astronomical wisdom and expertise of its era. Finally, it had extended instructions inscribed on its protective plates, describing the phenomena which it dealt with or offering technical notes about its use. It is obvious from the above that it was not built in order to serve a sole purpose. It was built for the development of knowledge. It was, most likely, an educational instrument, used for scholarly studies of the then known Cosmos.

The new investigation of the Antikythera Mechanism has created word-wide interest both among the scientific community and the public. Responding to the demand for updated and authoritative information, the Antikythera Mechanism Research Group has created a web site:

http://www.antikythera-mechanism.gr

where new results are posted, including answers to basic questions, articles, pictures, videos and other relevant information.

It is evident that the Antikythera Mechanism is a very important record of the ability of ancient Greeks to work with advanced technological problems, offering innovative solutions that, even with present day standards, we cannot fail to admire and respect.

\section{Acknowledgements}

It is a pleasure to thank the Antikythera Research Project group and the Director and personnel of the National Archaeological Museum of Athens. Without their research efforts and the safeguarding of the Antikythera fragments respectively, this work wouldn't have been initiated. 


\section{References}

[1] Unknown author, The findings of the Antikythera Wreck (in greek), Archaeological Ephemeris, 3rd Period, Issue $1 \& 2$, p. 145-173, 1902.

[2] V.R. Grace, The Commercial Amphoras, in G.D. Weinberg et. al., The Antikythera Shipwreck Reconsidered, TAPhS, New Series, 55/3, p. 5-17, 1965.

[3] P.C. Bol, Die Skulpturen des Schiffsfundes von Antikythera, MDAI (A) Beiheft 2, p. 119-120, 1972.

[4] G.D. Weinberg, The Glass Vessels, in G. D. Weinberg et al., The Antikythera Shipwreck Reconsidered, TAPhS, New Series, 55/3, p. 30-39, 1965.

[5] J.-Y. Cousteau (n. 4), H.E. Tzalas, Bronze Statues from the Depths of the Sea, in Great Moments in Greek Archaeology, Athens, p. 346, 2007.

[6] M. Jackson, New Jewellery Evidence from the Antikythera Shipwreck: A Stylistic and Chronological Analysis, BCH, 134, p. 178-194, 2010.

[7] N. Kaltsas, E. Vlachogianni \& P. Bouyia (eds), The Antikythera Shipwreck, National Archaeological Museum, Athens, 2012.

[8] D. de S. Price, Gears from the Greeks: The Antikythera Mechanism-A calendar computer from ca. 80 BC. Trans. Am. Phil. Soc., New Series, 64, p. 1-70, 1974 (reprinted by Science History Publications, New York, 1975).

[9] D. de Solla-Price, A History of Calculating Machines, Micro IEEE, 4, p.22-52, 1984

[10] M. Roumeliotis, Simulation and Animation of the Antikythera Mechanism, University of Macedonia, Thessaloniki, Greece, http://www.etl.uom.gr/mr/index.php?mypage=antikythera.

[11] A. G. Bromley, Observations of the Antikythera Mechanism, Antiquarian Horology, 18, p. 641652, 1990.

[12] M.T. Wright, A. G. Bromley, Towards a New Reconstruction of the Antikythera Mechanism, Proc. Conf. Extraordinary Machines and Structures in Antiquity. Ancient Olympia, p. 81-94, (ed. S.A. Paipetis, Peri Technon, Patras), 2003.

[13] M.T. Wright, Epicyclic Gearing and the Antikythera Mechanism, Antiquarian Horology, part 1, 27, p. 270-279, 2003 and part 2, 29, p. 51-63, 2005.

[14] M.T. Wright, A Planetarium Display for the Antikythera Mechanism, Horological Journal, 144, p. $169-173,2002$.

[15] M.T. Wright, The Antikythera Mechanism: a New Gearing Scheme, Bulletin of the Scientific Instrument Society, no. 85 p. 2-7, 2005.

[16] A. Ramsey, The latest techniques reveal the earliest technology - A new inspection of the Antikythera Mechanism, Proceedings of the International Symposium on Digital industrial Radiology and Computed Tomography, June 25-27, Lyon, France, 2007.

[17] T. Malzbender, D. Gelb, H. Wolters, Polynomial Texture Maps, Hewlett-Packard Laboratories, http://www.hpl.hp.com/ptm .

[18] A. Freeth et al. Decoding the ancient greek astronomical calculator known as the Antikythera Mechanism, Nature, 444, p. 587-591, 2006. 
[19] A. Freeth, A. Jones, The Cosmos in the Antikythera Mechanism, ISAW Papers, 4, 2012

[20] E. Gourtsogiannis, Hipparchus vs. Ptolemy and the Antikythera Mechanism: Pin-Slot Device models lunar motion, Journal of Advances in Space Research 46, 540-544 (2010).

[21] M.G. Edmunds, Journal for the History of Astronomy: xlii, p. 307-320, 2011

[22] M. Anastasiou et al. The astronomical events of the parapegma inscribed on the Antikythera Mechanism, J. Hist. Astronomy (accepted), 2012.

[23] A. Freeth et al, Calendars with Olympiad display and eclipse prediction on the Antikythera Mechanism, Nature, 454, p. 614-617, 2008.

[24] K. Efstathiou, A. Basiakoulis, M. Efstathiou, M. Anastasiou, J.H. Seiradakis, Determination of the gears geometrical parameters necessary for the construction of an operational model of the Antikythera Mechanism, Mechanism and Machine Theory, 52, 219-231, 2012. 